\title{
Educação do Distrito Federal perdeu bilhões com erros do Tribunal de Contas
}

\author{
Nicholas Davies \\ Universidade Federal Fluminense
}

\section{Resumo}

0 artigo analisou relatórios e decisões normativas do Tribunal de Contas do Distrito Federal sobre contas do Governo do Distrito Federal para averiguar como contabilizou receitas e despesas em educação desde os anos 1990 até 2010 e constatou uma série de falhas e inconsistências. Uma foi nunca registrar as receitas adicionais ao percentual mínimo, como o salário-educação e demais transferências federais para programas educacionais. A falha mais grave foi não contabilizar como acréscimo as astronômicas transferências federais $(R \$ 1,6$ bilhão em 2010) específicas para a educação do Distrito Federal, denominadas de Fundo Constitucional do Distrito Federal pelo menos até o final de 2008, quando tais transferências passaram a ser acrescidas ao mínimo. Pelo lado da despesa, o principal equívoco foi computar o pagamento de inativos como despesas da educação pelo menos até o final de 2008, quando eles foram excluídos do cálculo dos $25 \%$ vinculados à educação. Outro equívoco foi não esclarecer se as despesas consideradas no cálculo do mínimo são empenhadas, liquidadas ou pagas.

Palavras-chave: Financiamento da educação. Tribunal de Contas do Distrito Federal. Orçamento da educação. 


\section{Education in the Federal District has lost billions due to errors made by the Court of Accounts}

The article has examined reports of decisions taken by the Audit Office of the Brazilian Federal District on accounts of the Federal District Government, to check how it has calculated revenue and expenses on education from the 1990's to 2010, and found a number of errors and inconsistencies. One was to never register revenues which should be added to the minimum percentage of taxes linked to education, such as the payroll-linked contribution and other federal transfers for educational programmes. The most serious flaw was not to add to the minimum percentage the astronomical federal transfers (R\$ 1.6 billion in 2010) specific to Federal District education, the so-called Federal District Constitutional Fund, at least until the end of 2008, when such transfers began being added to the minimum percentage. Regarding expenses, the main mistake was to consider payment of retired educational personnel as education expenses at least until the end of 2008, when they were excluded from the calculation of the $25 \%$ of taxes linked to education. Another error was not clarifying if the expenses considered in the calculation of the minimum percentage were pending, liquidated or paid.

Keywords: Education funding. Audit Office of the Brazilian Federal District. Education budget.

\section{La Educación perdió miles de millones con el error del Tribunal de Cuentas}

El artículo analizó informes y decisiones normativas del Tribunal de Cuentas de Distrito Federal sobre las cuentas del gobierno de DF para averiguar cómo ha contabilizado ingresos y gastos en educación entre 1990 y 2010 y ha constatado una serie de errores e inconsistencias. Una fue nunca registrar los ingresos adicionales al porcentaje mínimo de impuestos, como las transferencias federales para programas educacionales. La falla más grave fue no contabilizar como incremento las astronómicas transferencias federales específicas para la educación del Distrito Federal, al menos hasta el final de 2008, cuando tales transferencias pasaron a ser aumentadas al mínimo. Con relación al gasto, el principal error fue considerar el pago de jubilados como gastos en educación hasta el final de 2008, cuando ellos fueron excluidos del cálculo del $25 \%$ de impuestos vinculados a la educación, una determinación de la Constitución Federal. Otro equívoco fue no clarificar los criterios adoptados en la clasificación de los gastos considerados en el cálculo del mínimo.

Palabras-clave: Financiamiento de la educación. Tribunal de Cuentas del Distrito Federal. Presupuesto de la educación. 


\section{Introdução}

Este artigo examina as instruções normativas adotadas pelo Tribunal de Contas (TC) do Distrito Federal na verificação da aplicação dos recursos vinculados à educação, sendo parte de uma pesquisa sobre o papel dos Tribunais de Contas (TCs) do Brasil nesta verificação. Isso é importante porque os governos procuram seguir (quando o fazem, é clarol as orientações dos TCs na sua prestação de contas, não necessariamente as disposições da LDB (Lei de Diretrizes e Bases da Educação Nacional - Lei 9.394/96) ou de pareceres e resoluções do Conselho Nacional de Educação (CNE). Daí a importância do estudo dessas interpretações para a avaliação menos imprecisa dos recursos vinculados à manutenção e desenvolvimento do ensino (MDE), conforme definido pelos artigos 70 e 71 da LDB.

Este estudo foi suscitado por outros estudos realizado nos últimos anos (Davies, $1999,2001,2004,2008)$, que demonstraram o problema da contabilização correta da receita e despesa vinculada à educação.

Esta pesquisa procurou obter as normas editadas pelos TCs desde a Lei Federal 7.348 (Brasil, 1985), que regulamentou a Emenda Constitucional Calmon (Brasil, 1983), restabelecendo a vinculação de recursos para a educação, eliminada pela Constituição imposta pela ditadura militar em 1967. A Lei 7.348 foi tomada como marco inicial porque desde 1967 não havia vinculação constitucional de recursos (restabelecida apenas para os municípios pela Emenda Constitucional no. 1 (Brasil, 1969) e porque ela vigorou integralmente até dezembro de 1996 (quando foi promulgada a LDB) e parcialmente a partir de janeiro de 1997, segundo a interpretação dada pelo Parecer no. 26/97 (Brasil, 1997) do CNE. Basicamente, esta Lei 7.348 foi importante porque definiu as receitas e despesas vinculadas à $\mathrm{MDE}$, conceito que mereceu uma definição menos elástica do que a permitida pela função orçamentária de 'Educação e Cultura', prevista na Lei Federal 4.320 (Brasil, 1964), que normatiza a elaboração e execução de orçamentos públicos. Desde 2001 essa função foi dividida em duas: uma para a educação (designada pelo número 12) e outra para a cultura.

Outras referências legislativas adotadas foram as Emendas Constitucionais 14 (Brasil, 1996a), que criou o Fundo de Manutenção e Desenvolvimento do Ensino Fundamental e de Valorização do Magistério (Fundef), em setembro de 1996, e 53 (Brasil, 2006), que criou o Fundo de Manutenção e Desenvolvimento da Educação Básica e de Valorização dos Profissionais da Educação (Fundeb), em dezembro de 2006, e as Leis 9.394 (Brasil, 1996b) e 9.424 (Brasil, 1996c), esta última regulamentou o Fundef, ambas de dezembro de 1996, e a 11.494 (Brasil, 2007a), que regulamentou o Fundeb.

Basicamente, as informações e documentos que se procurou obter junto aos TCs foram as seguintes:

(1) Legislação federal, estadual ou municipal adotada pelo TC para a averiguação 
das receitas e despesas vinculadas à educação ou, mais precisamente, à MDE, conforme definido na Lei 7.348 e nos artigos 70 e 71 da LDB. 0 objetivo era, por exemplo, o percentual mínimo que o TC considerava correto, no caso de o percentual das constituições estaduais, do Distrito Federal e leis orgânicas ser superior aos 25\% previstos na Constituição Federal (CF) de 1988.

(2) Instruções e normas internas elaboradas pelo TC para o cálculo das receitas e despesas vinculadas à MDE desde a Lei 7.348. Tais instruções são fundamentais porque os governos procuram seguir (quando lhes interessam, é clarol os procedimentos nelas contidos, não necessariamente a CF, a Estadual, a do DF, a Lei Orgânica municipal ou a legislação educacional.

(3) Definição dos impostos que compõem a base de cálculo do percentual mínimo. A intenção era saber, sobretudo, se eram computadas as multas e juros de mora dos impostos, a receita da dívida ativa de impostos (DAI), sua atualização monetária e as multas e juros de mora sobre a DAl.

(4) Contabilização dos ganhos, complementação federal e rendimentos financeiros com o Fundef/Fundeb, receitas do salário-educação, convênios ou repasses de natureza educacional (merenda e outros), e receitas de serviços prestados por instituições educacionais e operações de crédito para a educação. Eram/são contabilizados como parte do percentual mínimo ou como acréscimos (como deveriam) a ele? Este cálculo é importante porque muitas vezes os governos omitem tais receitas ou as incluem na base de cálculo do percentual mínimo, quando o correto é acrescentá-las integralmente ao mínimo.

(5) Critérios de cálculo do valor devido em educação: valores nominais ou valores reais, ou, em outras palavras, os valores devidos são corrigidos monetariamente? Esses critérios são fundamentais numa época de inflação alta e mesmo após a decretação do Plano Real, em julho de 1994, porque a inflação persistiu, embora relativamente baixa.

(6) Definição de despesas consideradas como MDE. É fundamental a clareza sobre essa definição porque não raro os governos confundem tais despesas com as realizadas na função orçamentária "Educação e Cultura", modificada para “Educação" a partir de 2001, mais ampla do que o conceito de MDE, ou com o órgão responsável pela educação.

(7) Critérios de cálculo das despesas em MDE - valores empenhados, liquidados ou pagos no ano. Essa diferenciação é fundamental porque não é incomum os governos considerarem os valores empenhados como os aplicados no ensino, mas cancelarem parte de tais empenhos no exercício seguinte, fraudando, assim, os valores supostamente aplicados no ensino.

(8) Procedimentos adotados pelos TCs tendo em vista a implantação obrigatória do Fundef, em 1998, e do Fundeb, em 2007.

Entendemos que as receitas vinculadas à educação estadual, distrital e municipal são as seguintes:

(a) no mínimo $25 \%$ lou o percentual maior previsto nas constituições estaduais, 
do DF e leis orgânicas municipais, conforme estipula a LDB) de todos os impostos (inclusive as multas e juros de mora de impostos, a receita da DAl, sua atualização monetária, suas multas e juros de mora e outros encargos); mais

(b) o ganho (inexistente no caso do DF) com o Fundef ou o Fundeb lou seja, a diferença positiva entre a contribuição para esses fundos e a receita com eles), a complementação federal para os dois fundos e o rendimento financeiro com eles, contabilizáveis como acréscimos ao percentual mínimo; mais

(c) as receitas integralmente vinculadas à educação (salário-educação, convênios, programas e demais repasses, sobretudo federais, etc. e operações de crédito vinculadas à educaçãol e os rendimentos financeiros com elas auferidos, também contabilizáveis como acréscimos ao percentual mínimo.

Vale lembrar que as receitas com o Fundef ou o Fundeb não devem ser confundidas com ganhos, os quais só acontecem quando a receita dos governos com esses fundos é superior à sua contribuição para eles. Nesse caso, devem ser contabilizados como acréscimos ao percentual mínimo. Porém, quando há perdas lou seja, quando a receita é inferior à contribuição), devem ser contabilizadas dentro do percentual mínimo. Nesse cálculo, não entram a complementação federal e o rendimento financeiro com os fundos, sempre contabilizados como acréscimos ao percentual mínimo, mesmo quando há perdas. No caso do Distrito Federal, não houve/não há ganhos nem perdas com os dois fundos porque não há municípios no DF, porém o rendimento financeiro com a receita dos fundos deve ser adicionada ao mínimo.

As despesas, por sua vez, se vinculam a essas receitas acima, devendo se classificar como MDE, conforme definido nos artigos 70 e 71 da LDB. As despesas pagas pelas receitas (c), mesmo classificadas de MDE, não são contabilizáveis no percentual mínimo ou nas receitas adicionais (ganho, complementação e rendimento financeirol oriundas do Fundef ou Fundeb. As despesas pagas com as receitas (a) e/ou (b) tiveram/têm as seguintes particularidades:

(1) de 1989 até 1996 , pelo menos 12,5\% (a metade dos $25 \%$ ) da receita (a) deveriam ter sido aplicados pelos estados, DF e municípios na erradicação do analfabetismo e na universalização do ensino fundamental, conforme determinado pelo art. 60 do Ato das Disposições Constitucionais Transitórias da CF de 1988. (Brasil, 1988)

(2) de 1997 a 2006, pelo menos 15\% (60\% dos 25\%) dos impostos deveriam ter sido aplicados por tais esferas de governo apenas na universalização do ensino fundamental, sendo que $15 \%$ de alguns desses impostos compuseram o Fundef, dividido entre o governo estadual e prefeituras de cada estado de acordo com o número de matrículas no ensino fundamental regular, bem como o peso de cada tipo de matrícula (1 ${ }^{\mathrm{a}}$ a $4^{\mathrm{a}}, 5^{\mathrm{a}}$ a $8^{\mathrm{a}}$, zona urbana, zona rural, educação especial). Da receita com o Fundef, pelo menos $60 \%$ deveriam ter sido destinados à remuneração dos professores (segundo a EC 14/96) ou dos profissionais do magistério (de acordo com a Lei 9.424/96) em exercício no ensino fundamental regular.

(3) entre 1997 e 2006, os impostos restantes (no máximo 10\%, se o percentual 
mínimo da constituição estadual, do DF ou da lei orgânica municipal for 25\%) poderiam ser utilizados em qualquer nível ou modalidade de ensino, com a única exceção dos municípios, que só poderiam aplicá-los no ensino fundamental ou na educação infantil, conforme previsto no art. 11 da LDB; os estados, por sua vez, deveriam destiná-los prioritariamente ao ensino fundamental e ao ensino médio, conforme prevê o art. 211 da CF.

(4) com a implantação do Fundeb (em 2007), constituído de percentuais provisórios de impostos em 2007 e 2008 e definitivos (20\%) a partir de 2009, as despesas estaduais, distritais e municipais se dividem em dois grupos. 0 primeiro são as do Fundeb: as estaduais só podem ser empregadas no ensino fundamental e médio, enquanto as municipais se destinam somente à educação infantil e ensino fundamental. As do Distrito Federal devem ser aplicadas em toda a educação básica, ou seja, desde a creche até o ensino médio. Da mesma forma que no Fundef, pelo menos $60 \%$ das despesas do Fundeb se destinam à remuneração dos profissionais do magistério em exercício na educação infantil e no ensino fundamental (caso dos municípios) e no ensino fundamental e no ensino médio (caso dos Estados). No caso do DF, pelo menos $60 \%$ se destinam à remuneração de todos os profissionais do magistério em exercício na educação básica. 0 segundo grupo é formado por dispêndios financiados pela parcela restante dos impostos do Fundeb, ou seja, pelo menos os 5\% de diferença entre a contribuição para o Fundeb $(20 \%)$ e o percentual mínimo $(25 \%$, se for esse o percentual previsto na constituição estadual, do DF ou lei orgânical, e pelo menos os $25 \%$ dos impostos estaduais, distritais e municipais que não entram na formação do Fundeb (Imposto de Renda recolhido pelos governos estaduais, distrital e municipais, IOF-ouro, e IPTU, ISS, ITBII. No caso dos municípios, a receita de impostos fora do Fundeb continua sendo vinculada à educação infantil e ensino fundamental, conforme previsto no art. 11 da LDB.

\section{A documentação do TC e sua confiabilidade}

0 estudo se baseou nos relatórios do TC sobre as contas de 1994 a 2010 do governo do Distrito Federal (GDF) e nas suas decisões (que funcionam como instruções ou resoluções normativas) disponíveis no sítio do TC (www.tc.df.gov. br) e indicadas nas referências bibliográficas. Também levou em consideração os dados das receitas e despesas em MDE declarados pelo GDF nos formulários do SIOPE (Sistema de Informação sobre Orçamento Público em Educação) de 2006 a 2011, disponíveis no sítio do Fundo Nacional de Desenvolvimento da Educação (FNDE) ( www.fnde.gov.br), assim como as orientações da Secretaria do Tesouro Nacional (STN) para a contabilização dos recursos do Fundo Constitucional do Distrito Federal (FCDF) em 2003, 2004, 2005, 2007 e 2008. 
Uma primeira constatação é a frágil confiabilidade e/ou o pouco detalhamento dos dados. Em vários dos seus relatórios, o TC registra a dificuldade e/ou impossibilidade da contabilização precisa dos recursos da educação. Por exemplo, - Governo do DF teria como prática computar o pagamento de professores e outros servidores no Programa Administração, e não nos programas específicos (Educação da Criança de 0 a 6 anos, Ensino Fundamental, Ensino Médio, Ensino Supletivol. Esse lançamento incorreto teria impedido, nas contas de 1997, a comprovação do "atendimento do art. 60 do Ato das Disposições Constitucionais Transitórias, que determina a destinação de não menos de sessenta por cento dos gastos em manutenção e desenvolvimento do ensino ao ensino fundamental" (DF, TC, 1998, p. 209). 0 relatório sobre as contas de 1999, por sua vez, apontava que

[...] o acompanhamento das receitas e despesas relativas à educação vem sendo dificultado, entre outros motivos, pela ausência de classificação orçamentária que reflita com maior clareza os preceitos constitucionais e infraconstitucionais, assim como pelo fato de os correspondentes registros contábeis não mostrarem adequadamente os gastos concernentes às diversas esferas de ensino. (DF, TC, 2000b, p. 156)

0 relatório sobre as contas de 2002, por sua vez, registrava que

[...] tal como ocorrido no exercício de 2001, pela forma de operacionalização das rubricas destinadas ao cômputo dos limites relativos ao Fundef, não há como atestar o cumprimento dessa exigência constitucional/legal. Prevalecem as mesmas impropriedades apontadas como ressalvas em anos anteriores, como: ausência de informações para fins de aferição do cumprimento de normas constitucionais e infraconstitucionais do Fundef; e a não implementação deste Fundo na forma preconizada pela Lei 9.424/96. (DF, TC, 2003b, p. 300)

A falta de detalhamento e, portanto, a impossibilidade de verificação da aplicação dos recursos foi também constatada no relatório sobre as contas de 2006 :

Os recursos do Fundo Constitucional do Distrito Federal [...] continuam sendo executados no âmbito da União, por meio do Sistema Integrado de Administração Financeira Siafi, e não transitam no orçamento local. Com isso, as despesas com educação ficam classificadas em programa de trabalho genérico, o que impossibilita agregação direta com os recursos distritais geridos por meio do Siggo, bem como identificação em quais ações foram aplicados os valores. (DF, TC, 2007, p. 79)

A frágil confiabilidade dos dados pode ser exemplificada pelos formulários do SIOPE preenchidos pelo próprio GDF. Além dos $25 \%$ dos impostos, os governos têm uma receita adicional (salário-educação, convênios, transferências federais para programas como a merenda, transporte escolar etc.), que, obviamente, deveria corresponder às despesas por ela financiadas. Entretanto, os dados do SIOPE 
apontam discrepâncias todo ano. Em 2006 essa receita foi de $\mathrm{R} \$ 127$ milhões, porém a despesa paga por ela foi bem menor: $\mathrm{R} \$ 90$ milhões. Em 2008 a receita foi de $\mathrm{R} \$ 165,8$ milhões, mas a despesa foi maior: $\mathrm{R} \$ 175,8$ milhões. Algo parecido aconteceu em 2009, quando a despesa (R\$189,3 milhões) superou a receita (R\$ 183,4 milhões). Em 2010 a discrepância foi muito maior, pois a despesa (R\$ 687 milhões) foi mais de três vezes superior à receita (R\$200 milhões). A discrepância continuou em 2011, pois a despesa ( $\mathrm{R} \$ 714,7$ milhões) foi também mais de três vezes superior à receita adicional ( $\mathrm{R} \$ 227,9$ milhões). De onde terão vindo tais recursos adicionais (quase $R \$ 1$ bilhão considerando-se 2010 e 2011), não informados na tabela da receita do SIOPE? Certamente não do Fundo Constitucional do Distrito Federal, que, desde o SIOPE de 2009 , é contabilizado à parte dos $25 \%$ e de tais receitas adicionais. 0 estranho é que o TCDF não demonstra atenção para tais receitas adicionais em seus relatórios sobre as contas de 2009 e 2010 lo de 2011 ainda não estava disponível no sítio do TC em fevereiro de 2013), assim como nunca contabilizou, pelo menos nos seus relatórios que consultamos, tais receitas adicionais como acréscimos ao mínimo.

\section{A contabilização da receita}

O TC cometeu (e comete) várias falhas na contabilização da receita vinculada à educação, que não é o mesmo que receita de impostos vinculados à MDE. A vinculada à educação é mais abrangente, pois inclui também receitas que não entram nos $25 \%$, como o salário-educação e as várias transferências federais específicas para a educação. Já a de impostos se limita aos $25 \%$ dos impostos e não inclui as adicionais, vinculadas integralmente.

Uma primeira falha do TC e, portanto, também do GDF foi não computar na base de cálculo as multas e juros de mora sobre impostos, a receita da dívida ativa oriunda de impostos (DAl), sua atualização monetária e as multas e juros de mora sobre ela, segundo o ofício que endereçou a nós em 2000 (DF, TC, 2000a). Aparentemente, o TC só teria começado a contabilizar a DAl a partir de 2002, pois sua Decisão no. 5.898, de 2001 (DF, TC, 2001a), determinava a sua inclusão na base de cálculo, porém não as receitas de multas e juros de mora sobre impostos, sendo estas últimas incluídas pela Decisão no. 2.495, de 2003 (DF, TC, 2003a). Para se aquilatar o prejuízo causado por essa não inclusão, essa receita (multas e juros de mora sobre impostos, a DAl, sua atualização monetária e as multas e juros de mora sobre a DAll totalizou R $\$ 182$ milhões em 2010, segundo os dados declarados pelo GDF ao SIOPE. Como $25 \%$ desta receita são vinculados à MDE e não foram incluídos pelo menos de 1984 (primeiro ano do restabelecimento da vinculação constitucional de impostos para a MDE) até 2002 (total de 18 anos) na base de cálculo, a educação pode ter perdido centenas de milhões de reais com 
essa não inclusão durante esse período.

A principal irregularidade foi não contabilizar as transferências constitucionais específicas para o DF como acréscimos ao percentual mínimo (25\%), mas sim como parte da base de cálculo. Ora, tais transferências eram e são vinculadas integralmente à MDE e, por isso, deveriam ser computadas como acréscimos. São específicas do DF e não se destinam a nenhuma outra Unidade da Federação, sendo previstas no art. 21, inciso XIV da Constituição Federal de 1988 e transferidas durante muitos anos bem antes da sua regulamentação pela Lei 10.633 (Brasil, 2002), que criou o Fundo Constitucional do Distrito Federal (FCDF) em 2002. Tal contabilização equivocada foi normatizada pelo TC através da Decisão no. 4127, de 30/6/1999, que, no entanto, foi motivo de divergência entre os conselheiros do TC. Para o relator do processo (no. 2.785/98) que resultou na decisão, o conselheiro Jorge Caetano, essas transferências específicas, denominadas de voluntárias,

[...] mesmo se utilizadas para a manutenção e desenvolvimento do ensino público, não podem ser contabilizadas para tal fim. Não podem, portanto, ser contabilizadas para comprovar que os mínimos constitucionalmente estabelecidos foram cumpridos, ao contrário do que até hoje se fez no Distrito Federal, onde os recursos da folha de pagamento são custeados pela União, mediante transferências voluntárias. (DF,TC, 1999a)

Segundo o relator, se as transferências voluntárias fossem excluídas da base de cálculo, o limite mínimo de gastos em MDE não teria sido cumprido pelo Governo do DF. No entanto, a conselheira Marli Vinhadelli discordou do argumento do relator alegando que a Constituição Federal é genérica a respeito das transferências, pois apenas usa a expressão "compreendida a proveniente de transferências", e que a LDB fez uma restrição indevida ao acrescentar "constitucionais" após "transferências". A maioria dos conselheiros do TC discordou do relator nessa questão e foi favorável à inclusão das "transferências voluntárias para educação na apuração do percentual mínimo".

Para se ter uma ideia do prejuízo provocado por esta contabilização equivocada, tanto do GDF quanto do TC, em 2010 a parcela do FCDF destinada à educação totalizou $\mathrm{R} \$ 1,6$ bilhão e tal equívoco foi cometido pelo menos de 1984 a 2008 , isso porque 1984 foi o primeiro ano após a aprovação da Emenda Constitucional no. 24 (Brasil, 1983), conhecida como Emenda Calmon, que restabeleceu a obrigação dos estados, DF e municípios aplicarem no mínimo $25 \%$ dos impostos em MDE, e porque 2008 foi o último ano em que o TCDF aceitou esta contabilização equivocada, só corrigida em 2009, quando a parcela do FCDF destinada à educação passou a ser computada como acréscimo. Tendo em vista o montante de $\mathrm{R} \$ 1,6$ bilhão em apenas um ano e o número de anos em que tais transferências foram realizadas e não acrescidas ao mínimo, podemos estimar em talvez mais de duas dezenas de bilhões de reais o prejuízo para a educação distrital. Mesmo com a exclusão 
dos recursos do FCDF da base de cálculo a partir de 2009, eles continuaram sendo empregados equivocadamente, pois, do total de $R \$ 1,6$ bilhão em $2010, R \$ 1,1$ bilhão foi utilizado no pagamento de inativos, sobre o qual comentaremos mais adiante.

A interpretação de que tais transferências da União por meio do FCDF devem ser acrescidas ao mínimo é confirmada pelos Manuais do SIOPE. 0 de 2007, por exemplo, informa que a inclusão de tais transferência na base de cálculo "constitui procedimento sem amparo no art. 212 da Constituição Federal" e frisa que o art. 69 da LDB, ao mencionar

[...] compreendidas as transferências constitucionais, está-se referindo, tãosomente, aos impostos entregues por força da Constituição, não alcançando, pelas razões já expostas, as transferências realizadas ao Distrito Federal à conta do Fundo Constitucional do Distrito Federal, ainda que estas resultem de mandamento constitucional. [...] as despesas com o Fundo Constitucional do Distrito Federal não poderão ser consideradas no cômputo do percentual de aplicação em Manutenção e Desenvolvimento do Ensino - MDE, para fins de limite constitucional. (Brasil, MEC, FNDE, 2007, p. 46)

Também o parecer no 17, de 2008, do Conselho Nacional de Educação (Brasil, MEC, CNE, 2008), deixa claro que o FCDF é fonte adicional de financiamento para o ensino público do DF, ou seja, o DF deve destinar integralmente $1100 \%$ do valor do FCDF discriminado e estabelecido para a educaçãol o montante para MDE.

A Secretaria do Tesouro Nacional (STN), por sua vez, oscilou nas suas orientações sobre a contabilização do FCDF pelo GDF. Enquanto as 3a $4^{\mathrm{a}}$. e $5^{\mathrm{a}}$. edições (Brasil, STN, 2003, 2004, 2005, respectivamente) dos seus manuais para a elaboração do relatório resumido da execução orçamentária estipulavam que o FCDF deveria ser incluído na base de cálculo do percentual mínimo, as edições 7 (Brasil, STN, 2007) e 8 (Brasil, STN, 2008) continham orientação contrária.

Outro equívoco, pelo menos por parte do TCDF, foi não contabilizar ou pelo menos não registrar explicitamente as demais receitas adicionais aos $25 \%$, como a do salário-educação, merenda, transporte escolar etc. A importância dessas outras receitas adicionais pode ser aquilatada pelo fato de em 2010 elas terem totalizado R\$ 200 milhões, segundo os dados informados pelo GDF ao SIOPE.

Um aspecto interessante do TC e incomum em tribunais de contas é que ele, pelo menos em alguns anos, verificou se houve demonstrativo dos recursos repassados aos órgãos da educação, conforme preveem o art. $69, \S 5^{\circ}$ da LDB e também o inciso XIV do art. 138 do Regimento Interno do TCDF. 0 relatório das contas de 2005 registra que isso não teria acontecido em 2002, 2003, 2004 e 2005. (DF, TC, 2006, p. 339) 


\section{A contabilização das despesas}

Esta contabilização apresentou vários problemas. Um é que, por não serem detalhadas, não há como saber com exatidão se elas correspondem à definição de MDE, conforme preveem os artigos 70 e 71 da LDB. De qualquer modo, o TC excluiu corretamente gastos que, embora lançados na rubrica de Educação e Cultura (até 2000) ou Educação (desde 2001), não poderiam ser computados em MDE, como cultura, desporto, assistência social e médica nas escolas. A Decisão 5.898, de 2001 (DF, TC, 2001a), fundamentada no inciso IV do art. 71 da LDB, exclui despesas relativas à concessão de benefícios a servidores (vale-transporte, auxílioalimentação, auxílio-creche), programas de governo destinados à assistência social e outras similares, o que pode indicar que, em anos anteriores, tal inclusão era feita.

0 grande equívoco do TC e também do GDF foi incluir no cálculo do percentual mínimo aplicado em MDE o pagamento dos inativos da educação. É verdade que o TC oscilou em sua interpretação. Em 1994, não incluiu os inativos em tal cálculo, divergindo do GDF, que, com a inclusão dos inativos, alegou ter aplicado $26,06 \%$ em MDE, ao contrário do TC, que apurou $21,41 \%$ e corretamente faz uma ressalva ao cálculo adotado pelo GDF, que "não deduz os valores retidos dos salários do pessoal ativo para pagamento das aposentadorias" (DF, TC, 1995a, p. 148). Entretanto, a síntese do relatório do TC sobre as contas de 1994 (DF, TC, 1995b) considerou correto o pagamento dos inativos com os recursos da educação, alegando que o entendimento predominante é o de que a Lei 7.348, de 1985, teria sido recepcionada pela Constituição Federal e que o Projeto de Lei de Diretrizes e Bases prevê "permissão para considerar os gastos com inativos e pensionistas". Em seus relatórios sobre as contas de 1995, 1996, 1997 e 1998, o TC registra dois cálculos diferentes (com ou sem inativos). Em 1995 (DF, TC, 1996, p. 226 ), o percentual teria sido de $28,71 \%$ (com a inclusão de inativos) e $22,17 \%$ (sem inativos). Em 1997, o percentual teria sido de $31,14 \%$ (com inativos) e $21,77 \%$ (sem inativos) (DF, TC, 1998, p. 205). 0 TC, em seu relatório sobre as contas de 1995, já não parece abraçar o mesmo entendimento que adotou nas contas de 1994, pois diz que

[...] muitos doutrinadores defendem que a Lei 7.348 [de 1985, que definia o pagamento de inativos como MDE] foi recepcionada pela Constituição, enquanto outros argumentam que os gastos com manutenção de pessoal inativos não podem ser incluídos no cálculo do percentual aplicado, já que não representam atividade de manutenção ou, tampouco, desenvolvimento do ensino. Além do mais, o montante recolhido pelos servidores para assegurar suas aposentadorias já é computado nas despesas de MDE. Dessa forma, ao incluir o retorno do montante aprovisionado, para pagamento de inativos e pensionistas, esses recursos estariam sendo duplamente considerados, o que distorceria o cálculo ao aumentar injustificadamente os recursos destinados à atividade. (DF, TC, 1996) 
No entanto, no relatório sobre as contas de 1997, o TC adotou uma posição sem nenhum fundamento:

A controvérsia, entretanto, foi apaziguada com o exame do processo de discussão e aprovação da Lei de Diretrizes e Bases da Educação Nacional, no qual ficou comprovada a intenção do legislador em incluir tais despesas na apuração do limite antes referido.

(TC, DF, 1998b, p. 203)

Ora, a LDB diz o contrário, pois estipula que quem estivesse em atividade alheia à MDE não poderia ser pago com os recursos da educação.

Foi só em 1998, através da Decisão no 1.084/98 (TC, DF, 1998a), que o TC formalizou a aceitação de inativos e pensionistas para efeito do limite mínimo de gastos em MDE, se bem que para os anos de 1997 e 1998. Para agravar, as decisões no 5.898, de 2001, e no 2.495, de 2003, permitiram que as despesas com inativos e pensionistas fossem consideradas na apuração da aplicação na manutenção e desenvolvimento do ensino fundamental e do FUNDEF, este último destinado apenas a quem estivesse em exercício no ensino fundamental, o que claramente não era o caso dos inativos.

Só em 2008 essa interpretação foi alterada, pela Decisão no 8.187 (DF, TC, 2008b), que estipulou que os recursos do FCDF e os gastos com inativos e pensionistas da educação deixariam de constar das aplicações em MDE e no Fundeb a partir de 2009. De qualquer modo, o prejuízo com a contabilização equivocada dos inativos em MDE foi enorme, o que pode ser aquilatado pelo fato de em 2010 eles terem absorvido cerca de $\mathrm{R} \$ 1,1$ bilhão do $\mathrm{R} \$ 1,6$ bilhão do FCDF transferido à educação.

Outro problema é que o TC nunca esclareceu se ele se baseia em despesas empenhadas, liquidadas ou pagas, distinção fundamental, pois muitos empenhos de um exercício não são nele liquidados e podem ser cancelados em exercício posterior, distorcendo, assim, o cálculo exato do valor aplicado em MDE. É verdade que a Decisão no 5.898, de 2001, previu que a apuração dos limites mínimos de aplicação devia ser feita com base na despesa liquidada, "adicionando-se a ela, ao final do mesmo exercício, os restos a pagar processados e não processados", decisão repetida na Decisão no. 2.495, de 2003, o que pode indicar que o GDF não vinha se baseando em despesas liquidadas. Entretanto, o próprio TC nunca deixou claro em seus relatórios se o montante que considera aplicado em educação corresponde a valor empenhado, liquidado ou pago.

Com relação à exigência do $\S 4^{\circ}$ do art. 69 da LDB, que prevê que, se os valores devidos ( $25 \%$ dos impostos) não forem aplicados em um trimestre, serão corrigidos e aplicados no seguinte, pelo menos até 2000 o TC não fazia essa fiscalização, porque "a fixação do orçamento da educação e a publicação da sua execução [...] não ocorrem com o detalhamento requerido pelo $\S 4^{\circ}$ do art. 69 da LDB" (DF, TC, 2000a). Porém, a Decisão no. 5.898, de 2001, estipulou que "as diferenças apuradas 
a menos entre as receitas e as despesas previstas e as efetivamente realizadas [...] devem ser compensadas no trimestre seguinte" (TC, DF, 2001a), decisão reiterada pela Decisão no. 2.495, de 2003 (TC, DF, 2003a), o que pode indicar que o GDF não vinha cumprindo a decisão anterior.

\section{Considerações finais}

Este estudo dos relatórios do TC sobre as contas do GDF e também de algumas de suas decisões, assim como de outros documentos (relatórios do SIOPE, manuais da STN para a elaboração do relatório resumido da execução orçamentária), permitiram as seguintes conclusões. Uma é que a prestação de contas do GDF, segundo o TC, deixou bastante a desejar, pois os dados muitas vezes não eram detalhados e confiáveis. Apesar disso, o TC conseguiu apontar várias irregularidades nas contas do GDF, embora sempre as aprovasse. Outra é que a educação perdeu volume significativo de recursos legalmente devidos porque o TC (e presumivelmente o GDF) durante muitos anos não computou na base de cálculo as multas e juros de mora de impostos, a DAl, sua atualização monetária e suas multas e juros de mora da DAI ou incluiu equivocadamente nessa base as transferências específicas (o FCDF) do governo federal para a educação do $\mathrm{DF}$ (R\$ 1,6 bilhão só em 2010), que, por serem vinculadas integralmente à educação, são acréscimos integrais, não parciais. A contabilização equivocada dessas transferências só foi corrigida a partir de 2009. Outra falha do TC foi nunca mencionar, nos relatórios, as demais receitas adicionais ao percentual mínimo (salário-educação, por exemplo). Entretanto, em alguns anos o TC fez algo incomum em tribunais de contas, que é verificar se os recursos são repassados ao órgão responsável pela educação, conforme previsto pela LDB.

$\mathrm{Na}$ contabilização das despesas, o principal equívoco foi aceitar o pagamento dos inativos com os recursos da educação até 2008, embora o TC oscilasse na sua interpretação sobre isso em alguns anos da década de 1990. Os inativos foram excluídos do cálculo do percentual mínimo vinculado à MDE a partir de 2009, porém continuaram sendo pagos com parte significativa dos recursos educacionais do FCDF, o que é um contrasenso, pois não contribuem para manter nem desenvolver o ensino.

Outra falha do TC foi não esclarecer em seus relatórios se as despesas consideradas no cálculo do valor aplicado em MDE eram empenhadas, liquidadas ou pagas, embora no início dos anos 2000 ele já tivesse decidido que seriam consideradas as liquidadas.

Este breve levantamento permite concluir que a educação do Distrito Federal perdeu e talvez continue perdendo bilhões de reais vinculados legalmente a ela. 


\section{Referências bibliográficas}

BRASIL. Congresso Nacional. Constituição da República Federativa do Brasil. Brasília: Senado Federal, 1988. Disponível em <http://www.planalto.gov. br>. Acesso em: 10 fev. 2013.

Emenda Constitucional no. 1, de 17 de outubro de 1969. Altera a Constituição Federal de 1967. Diário Oficial da União, Brasília, DF, 20 out. 1969. Republicado com retificações em 30 out. 1969. Disponível em <http:// www.planalto.gov.br> Acesso em: 10 fev. 2013.

. Emenda Constitucional no. 14, de 12 de setembro de 1996. Modifica os arts. 34, 208, 211212 da CF e dá nova redação ao art. 60 do Ato das Disposições Constitucionais Transitórias. Diário Oficial da União, Brasília, DF, 13 set. 1996a. Disponível em: <http://www.planalto.gov.br/> Acesso em: 10 fev. 2013.

. Emenda Constitucional no. 24, de $1^{\circ}$ de dezembro de 1983. Estabelece a obrigatoriedade de aplicação anual, pela União, de nunca menos de treze por cento, e pelos Estados, Distrito Federal e Municípios, de, no mínimo, vinte e cinco por cento da renda resultante dos impostos, na manutenção e desenvolvimento do ensino. Diário Oficial da União, Brasília, DF, 5 dez. 1983. Disponível em: <http://www.planalto.gov.br>. Acesso em: 10 fev. 2013.

. Emenda Constitucional no. 53, de 19 de dezembro de 2006. Dá nova redação aos arts. $7^{\circ}, 23,30,206,208,211$ e 212 da Constituição Federal e ao art. 60 do Ato das Disposições Constitucionais Transitórias. Diário Oficial da União, Brasília, DF, 20 dez. 2006. Disponível em: <http://www.planalto.gov. $\mathrm{br} />$ Acesso em: $10 \mathrm{dez} .2010$.

. Lei no. 10.633, de 27/12/2002. Institui o Fundo Constitucional do Distrito Federal - FCDF, para atender o disposto no inciso XIV do art. 21 da Constituição Federal. Diário Oficial da União, DF, Brasília, 30/12/2002. Disponível em: <http://www.planalto.gov.br/>. Acesso em: fev. 2013.

. Lei no. 11.494, de 20 de junho de 2007. Regulamenta o Fundo de Manutenção e Desenvolvimento da Educação Básica e de Valorização dos Profissionais da Educação - FUNDEB, de que trata o art. 60 do Ato das Disposições Constitucionais Transitórias; altera a Lei no 10.195 , de 14 de fevereiro de 2001; revoga dispositivos das Leis nos 9.424, de 24 de dezembro de 1996, 10.880, de 9 de junho de 2004, e 10.845, de 5 de março de 2004; e dá outras providências. Diário Oficial da União, Brasília, DF, 21 jun. 2007. Disponível em: <http://www.planalto.gov.br/>. Acesso em: 10 dez. 2010.

. Lei no. 4.320, de 17 de março de 1964. Estatui Normas Gerais de Direito Financeiro para elaboração e controle dos orçamentos e balanços da União, dos Estados, dos Municípios e do Distrito Federal. Diário Oficial da União, Brasília, DF, 23 mar. 1964. Disponível em: <http://www.planalto.gov. $\mathrm{br} />$. Acesso em: $10 \mathrm{dez} .2010$. 
. Lei no. 7.348, de 24 de julho de 1985. Dispõe sobre a execução do $\S$ $4^{\circ}$ do art. 176 da Constituição Federal e dá outras providências. Diário Oficial da União, Brasília, DF, 24 jul. 1985. Disponível em: < http://www.soleis.adv. br/emendacalmon.htm>. Acesso em: 10 dez. 2010.

. Lei no. 9.394, de 20 de dezembro de 1996. Estabelece as diretrizes e bases da educação nacional. Diário Oficial da União, Brasília, DF, 23 dez. 1996b. Disponível em: http://www.planalto.gov.br/. Acesso em: $10 \mathrm{fev}$. 2013.

. Lei no. 9.424, de 24 de dezembro de 1996. Dispõe sobre o Fundo de Manutenção e Desenvolvimento do Ensino Fundamental e de Valorização do Magistério, na forma prevista no art. 60, $\S 7^{\circ}$, do Ato das Disposições Constitucionais Transitórias, e dá outras providências. Diário Oficial da União, Brasília, DF, 26 dez. 1996c. Disponível em: <http://www.planalto.gov. $\mathrm{br} />$ Acesso em: 10 dez. 2010.

MEC. Conselho Nacional de Educação. Parecer CEB (Câmara de Educação Básica) no. 17, de 6/8/2008 (Aguardando homologação). Consulta acerca dos recursos do Fundo Constitucional do Distrito Federal, criado pela Lei $n^{0}$ 10.633/2002, tendo como base o art. 90 da LDB e as atribuições inerentes ao Conselho Nacional de Educação, estabelecidas na Lei $n^{\circ}$ 9.131/95. Brasília, 2008. Disponível em: www.cne.gov.br. Acesso em: fev. 2013.

. MEC. CNE (Conselho Nacional de Educação). Parecer no. CP 26/97, de 2 de dezembro de 1997. Interpreta o financiamento da educação na LDB. Brasília, 1997. Disponível em <www.mec.gov.br>. Acesso em 10 jun. 1998.

MEC. FNDE. SIOPE (Sistema de Informação sobre Orçamento Público em Educação). Manual dos relatórios estaduais. Brasília, 2007.

MEC. FNDE. SIOPE. Relatórios das receitas e despesas em manutenção e desenvolvimento do Distrito Federal de 2006 a 2011. Brasília, 2011.

. Ministério da Fazenda. Secretaria do Tesouro Nacional. Coordenação geral de Contabilidade. Relatório resumido da execução orçamentária - Manual de elaboração aplicado à União e aos Estados, Distrito Federal e Municípios, no. 7. Brasília: Secretaria do Tesouro Nacional, 2007. Disponível em <http:// www.stn.fazenda.gov.br>. Acesso em: dez. 2008.

. Ministério da Fazenda. Secretaria do Tesouro Nacional. Coordenação geral de Contabilidade. Relatório resumido da execução orçamentária - Manual de elaboração aplicado à União e aos Estados, Distrito Federal e Municípios, no. 8. Brasília: Secretaria do Tesouro Nacional, 2009. Disponível em <http:// www.stn.fazenda.gov.br>. Acesso em: dez. 2008.

- Ministério da Fazenda. Secretaria do Tesouro Nacional. Coordenação geral de Contabilidade. Relatório resumido da execução orçamentária - Manual de elaboração aplicado à União e aos Estados, Distrito Federal e Municípios, 
no. 3. Brasília: Secretaria do Tesouro Nacional, 2003. Disponível em <http:// www.stn.fazenda.gov.br>. Acesso em: dez. 2008.

BRASIL. Ministério da Fazenda. Secretaria do Tesouro Nacional. Coordenação geral de Contabilidade. Relatório resumido da execução orçamentária - Manual de elaboração aplicado à União e aos Estados, Distrito Federal e Municípios, no. 4. Brasília: Secretaria do Tesouro Nacional, 2004. Disponível em <http:// www.stn.fazenda.gov.br>. Acesso em: dez. 2008.

. Ministério da Fazenda. Secretaria do Tesouro Nacional. Coordenação geral de Contabilidade. Relatório resumido da execução orçamentária - Manual de elaboração aplicado à União e aos Estados, Distrito Federal e Municípios, no. 5. Brasília: Secretaria do Tesouro Nacional, 2005. Disponível em <http:// www.stn.fazenda.gov.br>. Acesso em: dez. 2008.

DAVIES, Nicholas. O Tribunal de Contas e a educação: quem controla o fiscalizador dos recursos? Brasília: Plano, 2001.

Tribunal de Contas: faz as contas ou faz de conta na avaliação dos gastos governamentais em educação? Revista Brasileira de Estudos Pedagógicos, Brasília, n. 194, jan./abr. 1999.

. O financiamento da educação: novos ou velhos desafios? São Paulo: Xamã, 2004.

Fundeb: redenção da educação básica? Campinas: Autores

Associados, 2008.

DISTRITO FEDERAL. TCDF. Decisão No 1084, de 10/3/1998a. Brasília. Disponível em: <http://www.tc.df.gov.br>. Acesso em: fev. 2013.

TCDF. Decisão no. 1747, de 26/4/2011. Brasília. Disponível em: <http://www.tc.df.gov.br>. Acesso em: fev. 2013.

TCDF. Decisão no. 2495, de 29/5/2003a. Brasília. Disponível em: <http://www.tc.df.gov.br>. Acesso em: fev. 2013.

TCDF. Decisão no. 4127, de 30/6/1999a. Brasília. Disponível em: <http://www.tc.df.gov.br>. Acesso em: fev. 2013.

TCDF. Decisão no. 5898, de 11/9/2001a. Brasília. Disponível em: <http://www.tc.df.gov.br>. Acesso em: fev. 2013.

TCDF. Decisão no. 8187, de 9/12/2008a. Brasília. Disponível em: <http://www.tc.df.gov.br $\rightarrow$. Acesso em: fev. 2013.

. TCDF. Ofício no. 101. Brasília, fevereiro de 2000a. Resposta a nosso pedido de esclarecimentos sobre procedimentos adotados pelo TC para contabilização da receita e despesa em educação.

TCDF. Relatório analítico e parecer prévio sobre as contas do governador do Distrito Federal. Exercício de 1995. Brasília, 1996. Disponível em: <http://www.tc.df.gov.br>. Acesso em: fev. 2013.

TCDF. Relatório analítico e parecer prévio sobre as contas do governador do Distrito Federal. Exercício de 1996. Brasília, 1997. Disponível em: <http://www.tc.df.gov.br>. Acesso em: fev. 2013. 
DISTRITO FEDERAL. TCDF. Relatório analítico e parecer prévio sobre as contas do governador do Distrito Federal. Exercício de 1997. Brasília, 1998b. Disponível em: <http://www.tc.df.gov.br>. Acesso em: fev. 2013.

TCDF. Relatório analítico e parecer prévio sobre as contas do governador do Distrito Federal. Exercício de 1998. Brasília, 1999b. Disponível em: <http://www.tc.df.gov.br>. Acesso em: fev. 2013.

- TCDF. Relatório analítico e parecer prévio sobre as contas do governador do Distrito Federal. Exercício de 1999. Brasília, 2000b. Disponível em: <http://www.tc.df.gov.br>. Acesso em: fev. 2013.

TCDF. Relatório analítico e parecer prévio sobre as contas do governador do Distrito Federal. Exercício de 2000. Brasília, 2001b. Disponível em: <http://www.tc.df.gov.br>. Acesso em: fev. 2013.

TCDF. Relatório analítico e parecer prévio sobre as contas do governador do Distrito Federal. Exercício de 2001. Brasília, 2002. Disponível em: <http://www.tc.df.gov.br>. Acesso em: fev. 2013.

. TCDF. Relatório analítico e parecer prévio sobre as contas do governo do Distrito Federal. Exercício de 2002. Brasília, 2003b. Disponível em: <http:// www.tc.df.gov.br>. Acesso em: fev. 2013.

. TCDF. Relatório analítico e parecer prévio sobre as contas do governo do Distrito Federal. Exercício de 2003. Brasília, 2004. Disponível em: <http:// www.tc.df.gov.br>. Acesso em: fev. 2013.

. TCDF. Relatório analítico e parecer prévio sobre as contas do governo do Distrito Federal. Exercício de 2004. Brasília, 2005. Disponível em: <http:// www.tc.df.gov.br>. Acesso em: fev. 2013.

TCDF. Relatório analítico e parecer prévio sobre as contas do governo do Distrito Federal. Exercício de 2005. Brasília, 2006. Disponível em: <http:// www.tc.df.gov.br>. Acesso em: fev. 2013.

. TCDF. Relatório analítico e parecer prévio sobre as contas do governo do Distrito Federal. Exercício de 2006. Brasília, 2007. Disponível em: <http:// www.tc.df.gov.br>. Acesso em: fev. 2013.

TCDF. Relatório analítico e parecer prévio sobre as contas do governo do Distrito Federal. Exercício de 2007. Brasília, 2008b. Disponível em: <http:// www.tc.df.gov.br>. Acesso em: fev. 2013.

. TCDF. Relatório analítico e parecer prévio sobre as contas do governo do Distrito Federal. Exercício de 2008. Brasília, 2009. Disponível em: <http:// www.tc.df.gov.br>. Acesso em: fev. 2013.

TCDF. Relatório analítico e parecer prévio sobre as contas do governo do Distrito Federal. Exercício de 2009. Brasília, 2010. Disponível em: <http:// www.tc.df.gov.br>. Acesso em: fev. 2013.

. TCDF. Relatório analítico e parecer prévio sobre as contas do governo do Distrito Federal. Exercício de 2010. Brasília, 2011. Disponível em: <http:// www.tc.df.gov.br>. Acesso em: fev. 2013. 
Recebido em março de 2013

Aprovado em maio de 2013

Nicholas Davies possui graduação em História pela Universidade Federal Fluminense (1983), mestrado em Educação pela Universidade Federal Fluminense (1991) e doutorado em Sociologia pela Universidade de São Paulo (1999). Atualmente é professor associado da Universidade Federal Fluminense. Email: nicholasapq.cnpq.br 